\title{
NARRAR ATRAVÉS DE IMAGENS: A REPRESENTAÇÃO DA BATALHA DO SOMME POR JOE SACCO
}

\begin{abstract}
Valéria Sabrina Pereira ${ }^{1}$
Resumo: Às vésperas do centenário da Primeira Guerra Mundial, o quadrinista Joe Sacco publicou The Great War. July 1, 1916: The First Day of the Battle of the Somme, um panorama ilustrado com cerca de sete metros de comprimento, sem falas ou texto. Neste artigo, será discutido como a escolha do primeiro dia da Batalha do Somme como evento representativo da guerra, a perspectiva de apenas um dos lados (o britânico), e a apresentação do exército como "um único organismo" funcionam como argumentação nessa representação imagética da guerra. Também serão feitas considerações sobre o livreto que acompanha o panorama, e onde se encontram as notas de Sacco que funcionam como legendas informativas, junto a um texto do jornalista Adam Hochshild que narra o desenvolvimento dos acontecimentos do dia.
\end{abstract}

Palavras-chave: Primeira Guerra; Somme; Quadrinhos; Panorama.

Abstract: On the eve of the 100th anniversary of the First World War, the graphic novelist Joe Sacco published The Great War. July 1, 1916: The First Day of the Battle of the Somme, an illustrated panorama about seven meters long without any text. In this paper, it will be discussed how the choice for the first day of the Battle of the Somme as the event that should represent the whole war, the one-sided perspective (the British) and the representation of the army as "a whole organism" function as a sort of argumentation in this illustrated representation of the war. The booklet that comes together with the book will also be analyzed. It brings notes from the cartoonist Sacco that function as a sort of informative subtitle to the drawing, as well as a text by the journalist Adam Hochschild that narrates the events of that day. Keywords: First World War; Somme; Comics; Panorama.

1 Pós-doutoranda em Literatura Alemã na Faculdade de Filosofia Letras e Ciências Humanas da Universidade de São Paulo. E-mail: valeriasabrinap@gmail.com 
Às vésperas do centenário da Primeira Guerra Mundial, no final do ano de 2013, o quadrinista Joe Sacco publicou o seu mais recente trabalho The Great War. July 1, 1916: The First Day of the Battle of the Somme (A Grande Guerra. 1o de julho de 1916. O primeiro dia da Batalha do Somme). Sacco é jornalista por formação, e se especializou naquilo que batizou como "jornalismo em quadrinhos". No Brasil, ficou conhecido pelas publicações relativas aos conflitos na Palestina: Palestina (2001) e Notas sobre Gaza (2009). Para produzir esses livros, Sacco viajou para locais de conflito e apresentou, em quadrinhos, sua vivência, assim como os relatos que obteve de habitantes locais, em um formato que remete ao do documentário.

Diferentemente de seus outros trabalhos, The Great War não tem seu foco na vivência individual da guerra. O panorama apresenta o exército como um único organismo e a guerra como uma experiência coletiva. Na introdução à obra, o autor afirma que a ideia de um panorama ilustrado da Primeira Guerra teria surgido há quinze anos em uma conversa com um então colega de quarto em uma noite de bebedeira (SACCO, 2013b, p. 1). Quando o ex-colega Matt Weiland foi contratado como editor da W.W. Norton, era chegada a hora de realizar o projeto. Como solução para a publicação, Weiland sugeriu que seguissem o princípio do painel Manhattan Unfurled (Manhattan desdobrada, 2001) de Matteo Pericoli, uma publicação sanfonada que apresenta um detalhado panorama da costa de Manhattan em cerca de sete metros de comprimento. A sugestão foi acatada pelo autor:

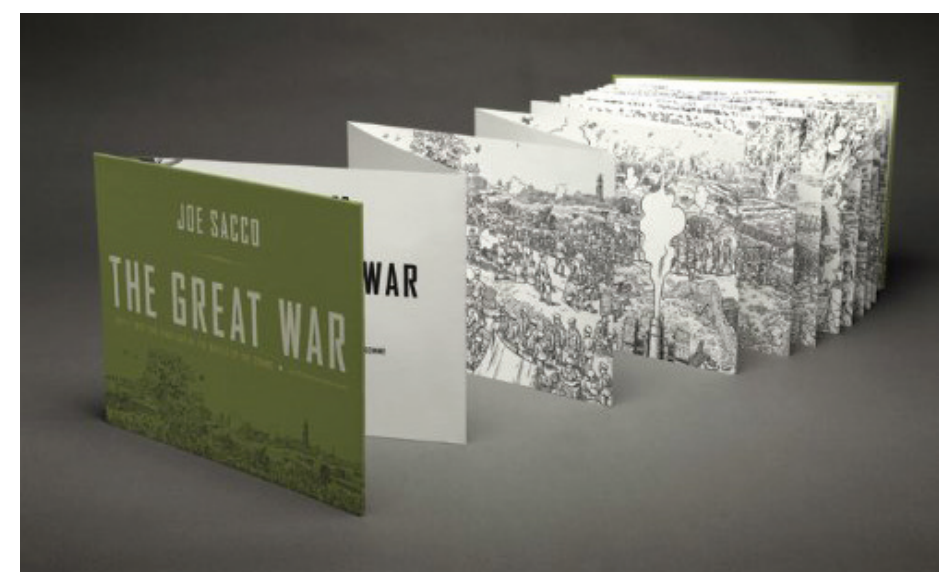

(Fonte: W.W. Norton - Divulgação)

Se a inspiração de Pericoli resolveu o problema editorial, ela ainda não resolvia o aspecto narrativo. A solução para esse problema foi encontrada por Sacco naquela que é considerada a primeira história em quadrinhos ocidental: a Tapeçaria de Bayeux. O tapete francês, tecido no século XI, narra em 68,38 metros e 58 cenas a conquista normanda da Inglaterra por Guilherme I. A tapeçaria serviu como inspiração não apenas para pensar a narrativa através de um panorama, mas também por questões técnicas, como afirma o autor, "Com a intenção de deixar o desenho compacto, eu reverenciei a arte medieval em outros meios estilísticos, por exemplo, dispensando a perspectiva realista e a proporção. [...] Contudo, tentei apresentar os detalhes, como a cozinha de campo e as ambulâncias a cavalo, da forma correta."2 (SACCO, 2013b, p. 1)

2 Todas as citações foram traduzidas por mim, exceto quando o contrário é indicado nas referências bibliográficas. 
A obra de Sacco pode ser apreciada de duas maneiras: como um painel que oferece um retrato detalhado da vida em campo durante a Primeira Guerra - caso no qual não há a necessidade do auxílio de explicações externas -, e como uma narrativa que se desenvolve na observação do panorama de aproximadamente sete metros, cuja compreensão integral necessita de explicações textuais, encontradas no livreto On the Great War (Sobre a Grande Guerra) que acompanha a publicação. Assim, vou comentar o painel em duas etapas, considerando as diferentes leituras possíveis.

\section{A REPRESENTAÇÃO PLÁSTICA DA GUERRA}

Apesar de apresentar muitas informações que excedem essa função, The Great War pode ser apreciado como uma representação plástica da Primeira Guerra. Em especial por apresentar com riqueza a experiência no exército, tanto na vida cotidiana quanto na guerra o que foi feito a partir de larga pesquisa em arquivos de fotos, além da leitura de livros sobre o tema. A partir do panorama de Sacco é possível observar desde detalhes da vida cotidiana, como a distribuição das refeições e o descanso, até a rotina da guerra, com a chegada das novas tropas, o abastecimento dos canhões, as trincheiras em seu formato em ziguezague precedidas dos arames farpados (então eram um importante impedimento ao inimigo), os mortos e feridos no front, e a rotina dos hospitais militares.

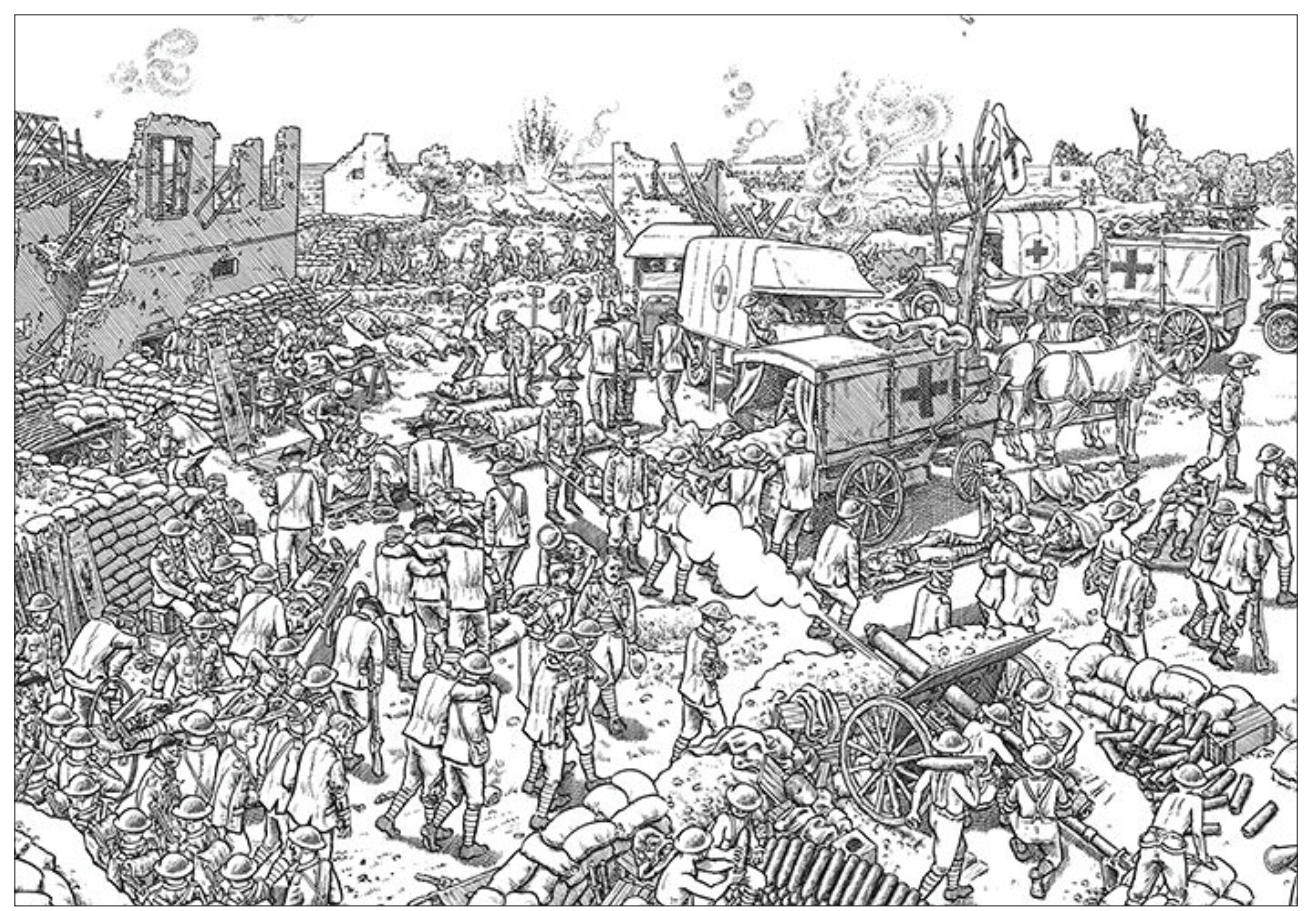

(Fonte: W.W. Norton - Divulgação)

Mesmo sem o auxílio de legendas, o panorama desenhado por Sacco é bem sucedido em efetuar uma pequena narrativa da guerra. O primeiro quadro apresenta altos comandantes na mais absoluta tranquilidade, longe do campo de batalha. Em seguida, há a representação da trincheira que, mesmo com a presença de homens operando artilharia, é 
tranquila, pois o que se vê de forma geral são homens rindo, cantando, comendo e descansando. Essa imagem mais tranquila é substituída por uma sequência que apresenta a espera nas trincheiras, a batalha com inúmeros atingidos, as estações de tratamento e o cemitério no quadro final. O discurso pacifista é feito sem nenhuma necessidade de legendas. Não se tratam de ações heroicas, de conquistas e da gloriosa vitória final - não nos esqueçamos de que a perspectiva escolhida por Sacco é também a do país vencedor -, mas sim da morte que aguarda a grande maioria dos envolvidos. Como afirma Susan Sontag no livro Diante da dor dos outros:

a argumentação contra a guerra não depende de informações sobre quem, quando e onde; o caráter arbitrário do morticínio implacável constitui prova suficiente. Para as pessoas seguras de que o certo está de um lado e a opressão e a injustiça estão do outro, e de que a luta precisa prosseguir, o que importa é exatamente quem é morto e por quem. (SONTAG, 2008, p. 14)

$\mathrm{Na}$ introdução da obra, Sacco salienta que optou por fazer uma representação da Batalha do Somme que focasse a perspectiva britânica devido ao fato de ter sido especialmente influenciado por esta já desde sua educação escolar (nos Estado Unidos). Mas essa decisão não se reflete apenas na escolha dos livros consultados, ou no fato de a perspectiva gráfica se dar a partir do lado britânico: o inimigo está completamente ausente, no panorama não há uma única representação física de um embate próximo. Essa escolha reforça ainda mais a tônica pacifista do livro (como será retomado mais adiante), mas também representa um dos mais importantes aspectos trazidos pela Primeira Guerra: com o forte avanço tecnológico bélico, a guerra não é mais realizada de homem para homem, pelo contrário, se torna cada vez mais comum que o inimigo não seja visto, ou, como afirma Paul Virilio (2005, p. 39) que homens atirem e não saibam precisar se foram responsáveis por alguma morte. Os soldados passam a matar sem ter plena consciência disso e sem sequer conhecer o rosto de suas vítimas. A Primeira Guerra traz com suas novas armas a despersonalização do inimigo.

\section{O ASPECTO NARRATIVO}

As intenções de Sacco, contudo, iam além do desenvolvimento de um panorama e incluíam o aspecto narrativo. Como a narração de toda a guerra se tornaria demasiado longa - tal qual a Tapeçaria de Bayeux -, uma única batalha foi escolhida, com ênfase especial em seu primeiro dia: a Batalha do Somme.

A Batalha do Somme foi a estratégia empregada pelos ingleses para auxiliar os franceses que atuavam no front de Verdun, onde havia um sério risco de perderem a guerra. A Grã-Bretanha interveio através de fortes ataques ao front alemão na região do rio Somme, com a intenção de obrigar a Alemanha a enviar reforços, retirando parte do seu efetivo da região de Verdun. Embora tenham sido bem sucedidos no intuito de aliviar os franceses em Verdun, a batalha do Somme é lembrada como um verdadeiro fiasco. Extremamente confiante de sua capacidade, o exército britânico foi à guerra sem contar com a possibilidade de 
derrota. Apenas na primeira hora, de um total de 60.000 homens, houve a baixa de 30.000 entre mortos e feridos. Ao final do dia, já se contavam 19.000 mortes. ${ }^{\circ} 1$ de julho de 1916 acabou, assim, conhecido como o dia que marcaria a perda da inocência e da confiança inabalável dos ingleses. A passagem escolhida por Sacco não fala de vitória, mas sim de um momento embaraçoso para o exército por uma série de estratégias mal pensadas.

Para que o painel sirva à memória desse evento, é necessário que hajam as devidas explicações sobre a seriedade do que é representado. Na segunda metade do livreto On the Great War, encontra-se uma miniatura do panorama com numeração e comentários. A legenda produzida por Sacco, além de explicar ao que as imagens se referem, muitas vezes dá conta de narrar aquilo que as ilustrações em nanquim não puderam traduzir. Por exemplo, a imagem de homens comendo na trincheira é acompanhada pela legenda: "O café-da-manhã chega, mas nem todas as tropas têm a chance de comer" (SACCO, 2013b, p. 12). Em outro ponto, pouco mais adiante, a legenda informa que a trincheira estava tão cheia que muitos tiveram que passar a noite da véspera de pé.

Mas o principal suporte textual da publicação é o texto "July 1, 1916" de Adam Hochschild (2013b). Em seu relato sobre os preparativos da batalha, Hochschild dá ênfase especial ao excesso de autoconfiança dos envolvidos aliado aseu despreparo. O despreparo surge em dois pontos em especial, sendo o primeiro deles o fato de que a totalidade dos soldados convocados para participar dessa batalha, apesar de todo o treinamento do qual seus superiores orgulhavam, não tinha absolutamente nenhuma experiência em campo de batalha. Os pelotões que se apresentaram no Somme eram massivamente formados por garotos de 18 a 21 anos, a grande maioria recém-egressos da escola. O segundo ponto se deve justamente ao caráter da guerra: mesmo os generais mais experientes não tinham uma noção clara de como deveriam lidar com as novas armas e técnicas agora utilizadas, como Hochschild coloca: "Arame farpado e metralhadoras tornaram impossível a guerra de avanços dramáticos e ataques gloriosos da cavalaria com a qual os generais de ambos os lados haviam sonhado." (HOCHSCHILD, 2013b, p. 4) Mas, apesar do desconhecimento sobre como aplicar e reagir às novas técnicas, o exército britânico conduziu a guerra com confiança e arrogância excessivas. O plano de guerra, com 31 páginas, já incluía os nomes com os quais as regiões deveriam ser rebatizadas após a conquista; o capitão W.P. Nevill deu para cada um de seus quatro pelotões uma bola de futebol americano e prometeu um prêmio àquele que a jogasse na trincheira alemã primeiro; e o comandante em chefe Douglas Haig chegou a escrever em seu diário, dois dias antes do ataque: "O arame farpado nunca esteve tão bem cortado, nem a preparação da artilharia tão perfeita.” (apud ibidem, p. 5) Acrescente-se a isso, que Haig ainda insistiu em técnicas antigas: três divisões de cavalaria esperavam para avançar após os homens terem limpado o caminho, o que Hochschild comenta com ironia: "Afinal de contas, gloriosos ataques por homens montados a cavalo não haviam sido um elemento decisivo em combates durante milênios?" (ibidem, p. 4)

Toda a segurança expressa por Haig, contudo, não dizia respeito ao conhecimento de resultados reais, mas à confiança na suposta perfeição do plano empregado. A tentativa de invasão ao front alemão foi precedida por sete dias de bombardeio ininterrupto, efetuados por canhões posicionados a cada seis metros por toda a linha do front aproximadamente. Além disso, houve ataques com gás e minutos antes de o exército britânico partir para o 
ataque, foram acionados três explosivos que haviam sido colocados sob a trincheira alemã. As vibrações do bombardeio foram sentidas até em Londres. Os comandantes britânicos estavam tão certos do sucesso de sua tática que informaram os soldados que não deveriam se preocupar, porque dificilmente algum alemão teria sobrevivido. Em outro livro, First Day of the Somme, o pesquisador Martin Middlebrook (2003) afirma que devido a essa segurança, os homens receberam ordens de avançar andando, e não correndo, para não se cansarem antes de chegar às trincheiras alemãs.

O fato é que o plano não funcionou. Como apontado por Hochschild, o ataque foi impressionante especialmente devido ao barulho provocado. Contudo, pelo menos um quarto das cápsulas não explodiram, e mais de dois terços foi completamente inútil para destruir as plataformas de artilharia alemãs, feitas de aço e concreto ou pedras. Mesmo o arame farpado só poderia ser destruído se as cápsulas explodissem exatamente em cima deles (HOCHSCHILD, 2013, p. 7), mas todos os homens da artilharia britânica eram inexperientes e não se podia esperar tal precisão deles (MACDONALD, 1993). Também deve se acrescentar que as trincheiras alemãs eram muito mais profundas e bem construídas do acreditavam os bretões - enquanto as trincheiras britânicas tinham a altura de um homem, as alemãs tinham em média 10 metros de profundidade, assim os bombardeios causaram um número muito limitado de mortes (MÜNKLER 2013, p. 451). Como aponta Hochschild, na manhã do ataque, com o simples uso de um binóculo já era possível se prever que a ação não havia sido bem sucedida, pois os arames farpados estavam em grande parte intactos, mas os generais preferiram prosseguir confiantes e não cancelar o ataque.

O texto de Hochschild é encerrado com uma menção ao capitão Nevill que nunca pôde premiar o pelotão que teria jogado a bola em primeiro lugar, pois morreu com um tiro na cabeça logo nos primeiros minutos, e outra ao tenente coronel E.T.F. Sandys que dois meses depois escreveu em carta a um amigo que "Eu nunca mais tive um momento de paz desde o dia $1^{\circ}$ de julho" (apud HOCHSCHILD, 2013, p. 8-9) e se suicidou com um tiro num quarto de hotel.

O texto de Hochschild é uma adaptação de seu livro To End All Wars. A Study of Loyalty and Rebellion, 1914-1916 (2011). O interessante é notar que essa obra não é citada por Sacco como uma das suas fontes de pesquisa, mas sim os outros dois livros acima citados para enriquecer a explicação do que foi a Batalha do Somme: First Day on the Somme (1971) de Martin Middlebrook e Somme (1983) de Lyn MacDonald. À pergunta sobre porque eles não foram utilizados para a introdução da publicação se oferecem muitas respostas. A primeira, e mais óbvia, é o fato de que o livro de Hochschild é uma publicação muito mais recente, além disso, seu texto é mais conciso do que o das outras obras, especializadas exclusivamente nessa batalha, e não na totalidade da guerra. Por outro lado, a comparação das três obras oferece outras respostas. Primeiramente, To End All Wars é notadamente pacifista. Hochschild relata o que aconteceu nos campos de batalha com grande ênfase nos erros cometidos e exalta toda a atuação de rebeldes e da oposição à guerra. Além disso, seu relato oferece uma importante complementação ao panorama: Enquanto Sacco ilustra as detalhadas descrições concedidas por Middlebrook e MacDonald, Hochschild não se atém a detalhes materiais, mas se ocupa principalmente do aspecto humano, retratando o excesso de confiança, a ansiedade e o sofrimento psicológico envolvidos no evento. 
Também deve ser notado que, apesar de o evento ser massivamente criticado na historiografia britânica, ambos os livros citados por Sacco são de caráter pró-militar. MacDonald (1993) escreve em tom ufanista e elogia a escolha dos soldados por serem homens bonitos, inteligentes e confiantes, e Middlebrook (2003), que abre o livro se declarando abertamente a favor da decisão pela Batalha do Somme, defende que, na Inglaterra industrial do início do século $\mathrm{XX}$, a possibilidade de não trabalhar em fábricas, mas sim a céu aberto (em combate) era uma excelente opção para os jovens. Apesar do posicionamento político, deve-se notar que o livro de Middlebrook, First Day on the Somme, se tornou um clássico sobre o assunto e é uma base evidente mesmo para o artigo de Hochschild. O livro também é apontado por Sacco como sua principal fonte e, de fato, o desenvolvimento de ações apresentado por Sacco é muito semelhante ao do estudo de Middlebrook, causando inclusive a impressão de que a sobreposição de ambos os trabalhos resultaria em algo como uma obra ilustrada (impressão que não é obtida, por exemplo, através da leitura de MacDonald). Entretanto, há duas diferenças cruciais entre as obras de Middlebrook e de Sacco.

A primeira delas trata da representação de Douglas Haig. Muito respeitado ainda durante a guerra, o comandante em chefe passou a ser fortemente criticado por historiadores a partir da década de 1960, quando chegou a receber o apelido de "Butcher Haig" (açougueiro Haig) devido ao elevado número de mortes sob o seu comando. Como Hochschild sinaliza, a principal crítica feita ao general era o fato de Haig ser muito ligado às antiquadas táticas de guerra e teimoso demais para aceitar que os tempos haviam mudado. Middlebrook, contudo, como defensor da guerra, também é um forte defensor de Haig e aponta seu subalterno, Henry Rawlinson, como o único responsável pela tragédia, uma vez que o plano de ataque foi desenvolvido por ele. O interessante é que, mesmo defendendo Haig, Middlebrook escreve relatos como o seguinte:

No meio tempo, ele esperava em seu quartel general avançado em Beauquesne. Ele podia ouvir claramente o som dos tiros, e ambulâncias já estavam passando pelo vilarejo ao lado [...]. Era um momento de muita ansiedade para Haig. Essa era a sua primeira batalha como comandante em chefe e uma para a qual ele tinha grandes esperanças. Mas ele não era um homem que se exaltava facilmente, e passou a manhã de forma suficientemente tranquila. (MIDDLEBROOK, 2003)

Ressalte-se que "tranquila", neste caso, quer dizer que mesmo percebendo que a batalha havia perdido o controle, Haig não partiu para o local dos acontecimentos até o cair da noite. Ele, inclusive, evitava fazer visitas aos hospitais militares, por sentir-se "fisicamente mal" com a visão dos feridos. Além disso, Middlebrook também informa que Rawlinson pediu que se enviasse 18 trens ambulatórios para atender os soldados. Haig, tão confiante que estava, enviou apenas três. Independente do grau de responsabilidade de Rawlinson pelo planejamento do ataque, Haig não pode deixar de ser considerado culpado por uma atitude absolutamente omissa.

Apesar de Middlebrook citar o nome de Rawlinson repetidas vezes, de forma a reforçar a sua culpa supostamente isolada pelos acontecimentos, Sacco desenha o panorama de forma que Haig seja a única pessoa a ser reconhecida. Mais do que isso, Haig é retratado 
três vezes em seguida - reforçando a ideia da passagem do tempo conforme movimentamos os olhos pelo painel -, sempre em situação idílica, como contraponto a todo o sofrimento e mortes que figuram no restante da obra.

Como segunda diferença vital, destaca-se o fato de os alemães serem figuras consideravelmente presentes na obra de Middlebrook. First Day on the Somme conta com muitos comentários de alemães sobre a batalha, várias descrições de embates corpo a corpo, assim como descrições de britânicos chegando (praticamente sozinhos) ao outro lado da trincheira. Além disso, o livro oferece um número considerável de fotos de soldados alemães em suas trincheiras.

Ao excluir os alemães e reforçar a imagem de Haig no início da obra, Sacco aponta o responsável pelo infortúnio. Se há um culpado pelo derramamento de sangue, ele não é o soldado inimigo, mas o comandante em chefe, o superior responsável pelo batalhão.

Sacco não apresenta o ponto de vista britânico apenas devido à perspectiva de seus homens, à ausência de ilustrações de alemães, ou às críticas a Haig, o fato é que até mesmo o recorte temporal é um sinal dessa perspectiva. O pesquisador alemão Münkler afirma que "praticamente nenhum acontecimento da guerra foi percebido de forma tão distinta pelos britânicos e pelos alemães como a Batalha do Somme" (2013, p. 448). Enquanto a Grã-Bretanha tende a abordar a batalha apenas através do fracasso do primeiro dia, o primeiro de julho, historiadores na Alemanha tratam a batalha como um todo, desde os severos bombardeios prévios iniciados em 24 de junho até o final em 19 de novembro de 1916. Da perspectiva dos alemães, trata-se de uma batalha que quase decidiu a guerra, e que é recordada por sua dificuldade e pela longa duração. Mesmo no que se refere à semana antecedente ao ataque, se por um lado os bombardeios não conseguiram produzir tantas mortes e estragos como desejado pelos ingleses, por outro, eles deixaram os alemães em estado de exaustão após dias sem dormir, e temendo a morte, como é descrito pelo autor Ernst Jünger (2013, p. 97) em suas memórias da Primeira Guerra. Também vale mencionar que além de Jünger, essa batalha que teve a participação de outra figura proeminente: Adolf Hitler, que nela sofreu um ferimento por estilhaço que o deixou internado por dois meses.

Além de ter ocorrido exatamente no meio da Primeira Guerra, o Somme foi a batalha que marcou a perda da inocência de ambas as partes envolvidas, quando tiveram de aceitar que a guerra agora não era feita apenas com novas tecnologias, mas também com o elevado desperdício de vidas. A Batalha do Somme foi a responsável pelo maior número de mortes em toda a Primeira Guerra, tendo consumido mais de um milhão de vidas, e a escolha pela sua representação como evento central é acertada principalmente por evitar armadilhas como a consagração ou a demonização de um dos lados.

\section{REFERÊNCIAS}

HOCHSCHILD, Adam. To End All Wars. Oxford: Macmillan, 2011. (ebook) "July 1, 1916." In: SACCO, Joe. On the Great War. Author's Note. New York: W.W. Norton, 2013b. p. 3-9. 
MACDONALD, Lyn. Somme. [1983] London: Penguin Books, 1993. (ebook)

MIDDLEBROOK, Martin. The First Day on the Somme. [1971] London: Penguin Books, 2003. (ebook)

MÜNKLER, Herfried. Der Große Krieg: Die Welt 1914 bis 1918. Berlin: Rowohlt, 2013.

JÜNGER, Ernst. Tempestades de Aço. Tradução Marcelo Backes. São Paulo: CosacNaify, 2013.

SACCO, Joe. The Great War. New York: W.W. Norton, 2013a.

On the Great War. Author's Note. New York: W.W. Norton, $2013 \mathrm{~b}$.

SONTAG, Susan. Diante da dor dos outros. Tradução Rubens Figueiredo. São Paulo: Companhia das Letras, 2008.

VIRILIO, Paul. Guerra e Cinema. Tradução Paulo Pires. São Paulo: Boitempo, 2005. 
